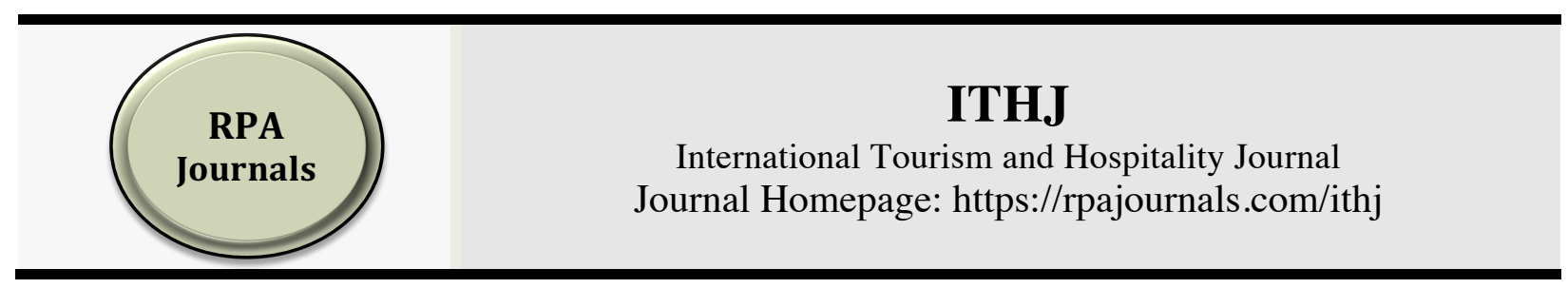

\title{
An Assessment of the Impact of COVID-19 Pandemic in the Tourism Sector in Tanzania
}

\author{
Ernest Elisha Mwamwaja" \\ Shogo Mlozi ${ }^{2}$ \\ Sokoine University of Agriculture, Tanzania' \\ Open University of Tanzania \& National College of Tourism, Tanzania ${ }^{2}$
}

\begin{abstract}
The aim of this study is to assess the impacts caused by COVID-19 in the tourism sector in Tanzania. Two major sources of data which was collected between March and May 2020 was social media and literature. COVID-19 led to lack of international visitors which directly affected the level of tourism activity and in some cases closure of businesses in the sector. Loss of business forced establishments to lay off part of its workforce and those who could be retained had to accept salary and wage cuts. Similarly, public institutions experienced significant reduction in tourism revenue. One of the major effects of this was a loss of their capacity to invest in product development, the initiative which had gained momentum in 2019. With limited spending power, future travellers are likely to be highly cost-sensitive, meaning that, high-cost destinations, such as long-haul destinations in Sub Sahara, shall be mostly affected. Despite the negative impacts, COVID-19 has triggered positive changes in destinations. With the shrinking size of inbound markets, industry operators have developed an unprecedented interest in domestic markets. On the other hand, the pandemic has helped players from public and private sectors to commit towards a common goal.
\end{abstract}

Keywords: : COVID-19 Pandemic, Tourism, Impact, Tanzania

*Corresponding author: Ernest Elisha Mwamwaja; E-mail: emwajas1@yahoo.co.uk DOI: https://doi.org/10.37227/ITHJ-2020-02-56

\section{Introduction}

Travel and tourism are arguably the largest and fastest growing sectors in the world. With an annual average growth of $4.6 \%$ (as of 2017) these sectors had outpaced global economic growth (3\%) for seven years in a row (Sofronov, 2018). According to ICAO (2018), in 2017 tourism industry employed 313 million people and generated $10.4 \%$ of global gross domestic product (GDP). WTTC (2018) reports further that travel and tourism supported 1 in every 10 jobs globally while they accounted for 1 in 5 of all jobs created across the world over the past five years. In Africa tourism alone contributes 8.5 percent (equivalent to $\$ 194.2$ billion) of the continent's Gross Domestic Product (WTTC, 2018). With the continent's 5.6 percent annual growth (in 2018), the continent is considered to be the 
second fastest growing tourism region in the world whose recorded annual growth was 3.9 per cent.

COVID-19 is a global crisis believed by many to be the most destructive epidemiological phenomenon in modern times. Despite collective effort to combat the pandemic there is still a limited medical capacity for treatment thus making nonpharmaceutical interventions the main strategy to contain the pandemic. While medical and other scientists work hard for a permanent solution to the scourge, the number of new cases and deaths continue to rise. Hall et al., (2020) noted that by $22^{\text {nd }}$ April, 2020, over 2.5 million cases and 180,000 deaths were reported worldwide. Although this number is already staggering, it could be much higher if not for significant underreporting by some countries (ibid, 2020).

Travel and tourism are probably the most affected sectors in the global economy and the reason for this is rather obvious. You need to travel, preferably covering considerable distances, if you are to engage in tourism, and for tourism in destinations to survive. Incidentally, it is this travelling that was to be restricted as one of measures to curtail new cases.

The main purpose of this paper is to contribute to the discussions already underway across the globe on the nature and magnitude of impact that COVID-19 has had to the tourism industry. While there is no shortage of studies on impacts that different natural and man-created phenomena have on tourism, the COVID-19 outbreak stands to be different from most others particularly in relation to the sheer scale of the impact which seems to have affected all businesses across the sector, big and small. It is important therefore that such impacts, and the manner they have occurred, are thoroughly studied. It is this knowledge that shall prove useful should other phenomena of the same nature re-occur in the future.

\section{Literature Review}

COVID-19 is an acute and severe respiratory syndrome whose origins are traced to Wuhan, China. First cases of the disease were reported on 31" December 2019. While Morens et al., (2009) appreciates the challenge of defining the word pandemic, Hall et al., (2020) adopts a rather descriptive approach to its definition. Hence, they provide common parameters by which the disease can be best understood. According to the authors pandemic is characterized by the following characteristics: wide spatial distribution, normally at a global scale; spreading is via transmission that can be traced from location to location; has potential for high attack rates where multiple cases appear within a short time; minimal population immunity; and associated with novel variants of existing organisms.

Studies on the nature, type and impact of disasters on international tourism have dominated the interest of researchers and practitioners since the early beginnings of travel and tourism as a global phenomenon. It is safe to assume that ties between tourism to epidemiology will forever be strong. This is because of inter-connections that exist between the two (Gossling, 2020). For a larger part, tourism is seen as both a contributor to disease spread and its economic consequences and at the same time is affected by it. Bur at the same time, crises and disaster vary considerably, while some have limited impact in their spatial and temporal scale, others that inflict far reaching consequences. Despite the differences however, it is the threat to security they impose that makes disasters detrimental to tourism (Tarlow, 2005). 
Globally, travel and tourism industries have been hit by a number of crises in the past. Such major disruptive events include the September 11 terrorist attacks in 2001 in the US soil, also in East Africa (Kenya and Tanzania). There also came a Severe Acute Respiratory Syndrome (SARS) outbreak in 2003, the global economic crisis in 2008/2009, and the Middle East Respiratory Syndrome (MERS) outbreak in 2015 (Gössling et al., 2020). While record shows us a series of such occurrences in history, there is already every indication that none of above crises have led to a large-scale decline in global development of tourism as COVID-19 (World Bank, 2020).

The COVID-19 situation is exceptional in every sense. Within a brief period of a few months, the world has seen tourism system moving from over-tourism (Dodds and Butler, 2019; and Seraphin et al., 2018) to virtually no tourism. This was made evident by a plethora of still and motion pictures taken from across the world showing what the situation was like immediately before and after the outbreak (Conde Nast Traveler, 2020). The pandemic also attracted different predictions as to what will travel and tourism be like in the aftermath. While some were understandably cautious, others seemed outright unrealistic trying to offer unusually promising outlook (Forbes, 2020).

Prior to COVID-19 outbreak the total and direct contribution by tourism to global GDP by 2029 was expected to reach 11.5 percent and 3.5 percent, respectively (ILO, 2020). Directly and indirectly, the sector accounted for some 319 million jobs worldwide in 2018 which is equivalent to 10 percent of total global employment (WTTC, 2019). For every directly created tourism job, almost one and a half additional jobs are created on an indirect or induced basis. Owed to its pervasiveness, anything that affect tourism negatively will definitely go beyond the borders of the sector. For this reason, the interest should also be cast on studying the impact that the sector has to its multiplier chain. In its totality therefore, the impact that COVID-19 has on tourism should also be seen in a range of other sectors including accommodation, food and beverage, agriculture, arts and crafts, etc. (ILO, 2020).

As dust begins to settle the world is now realizing that the impact that COVID-19 has on tourism at a global level is certainly beyond measure. The fuller impact might be on a scale not yet seen in our lifetime. In his foreword note in the report on the impact of COVID-19 in Tanzania, the country's UN Resident Coordinator, Mr. Zaltan Milisic, had this to say:

"We have also witnessed the tremendous magnitude and speed of collapse in economic activity - something unseen in our lifetime... The pandemic has led the global economy to a new conundrum. Global growth is projected by the International Monetary Fund (IMF) to fall to 3 percent this year, making it the worst recession since the great depression and much worse than during the 200809 financial crisis”. (ESRF, 2020)

Perception of risks at a destination is one of the critical factors that travelers use when processing their destination choices. It is a fact that any rational person will normally put life over everything else, hence, pandemics and other forms of crises tend to prompt visitors to either postpone their visits or avoid a particular destination altogether (Bhati et al., 2016). In addition, the impact of disasters on destinations is not only viewed on the number of arrivals or visits lost but also time it takes to restore pre-disaster travel traffic. Conversely, while tourists are aware that disasters are capable of inflicting negative effects on people and property at destinations they would not want to live with such memories for 
long. Unfortunately, however, such memories may take time to fade especially when the mainstream and social media do its best to propagate them (Rossello, 2020). The message shared by the media on impacts of disasters in destinations may range from human suffering, property damage, economic and social disruption to ultimate loss of life. So, depending on the scale of damage caused, this negative publicity may last for relatively longer period long enough to cover entire holiday season(s).

Estimates as to the extent of the impact of COVID-19 to tourism sector or the entire economy were produced by different sources. For example, in April 2020, the UN Department of Economic and Social Affairs (2020) estimated that the prevailing restrictions on economic activities in OECD countries, if extended until the middle of the second quarter, was projected to shrink economic growth by approximately $0.9 \%$ in 2020 , down from the forecast of $2.5 \%$ growth. The report further noted that this is likely to undermine efforts to achieve the 2030 sustainable development goals, which is likely to be more devastating in lower income countries.

According to UNWTO (2020), almost all international destinations introduced some form of (international) travel restrictions during COVID-19 pandemic which inflicted probably the deadliest blow to travel and tourism industries worldwide. Estimates by UNWTO show that 97 destinations (equivalent to $45 \%$ of all destinations) have totally or partially closed their borders for tourists, 65 destinations (or 30\%) suspended totally or partially international flights, and 39 destinations (18\%) closed their borders to travelers either from specific or all countries of origin.

It is this restriction in travel and tourism spending that led to systematic shutdown of business and income opportunity to people. WTTC, (2020) puts prediction of job loss and jobs at risk worldwide as a result of COVID-19 to be as high as 50 million representing a reduction of between 12 and14 percent. This is in addition to the anticipated loss of up to US\$2.1 trillion in the global economy in 2020. Other sources further claim that, when the outbreak will be over, it could take up to ten months for the industry to show signs of recovery (WEF, 2020). In one of exclusive interviews, the Chief Executive Officer of WTTC, said COVID 19 is the biggest threat to the tourism industry we have known to date and could be responsible for the shrinking of the travel sector by up to $25 \%$ in 2020 (BBC, 2020).

The obvious characteristic of the COVID-19 which sets it apart from all other pandemics is its unpredictability and the pace at which it evolved. Using its dynamics and nature of policy responses as parameters for analysis UNWTO (UNWTO, 2020a), in its press release of $6^{\text {th }}$ March 2020, estimated that the pandemic would cause international tourist arrivals to decline by at least 1 to $3 \%$ down from the forecasted growth of $3-4 \%$. Three weeks later, on $26^{\text {th }}$ March, this assessment was updated to a 20 to $30 \%$ loss in international arrivals which translate into tourism receipts loss of between US\$300 and 450 billion (UNWTO, 2020b). Among other challenges, the frequency of updates and a gap between one estimate and next demonstrate the difficulty of projections of the impact and true dimensions. Hence, a caution would be needed when interpreting its consequences on tourism or any other sectors. At best, published estimates are indicative at present.

\section{Research Methodology}

There are two main methods that the study used in collecting data for discussion. Most data were gathered through social media network, which has over the years proved to be a useful and reliable source of data (Kapoor, et al, 2018; and Branthwaite \& Patterson, 2011). Researchers of this paper are members to the largest WhatsApp group that was 
specifically established to allow key tourism industry players to (independently and freely) discuss matters that affect the industry in Tanzania. This is also used as one of the avenues through which the industry raises their recommendations to the government for action. The platform was established over the last two years and has a size of 215 members drawn from both public and private sectors. Its members are picked in a manner that all segments of the tourism sector are covered which include tour operation companies, accommodation facilities, custodians of tourist attractions, officials from marketing and tourism management organizations, training institutions, and tour guides. Data for the study through this media was collected for the period of two months i.e. from March 13 $3^{\text {th }}$ to May $15^{\text {th }}$ This represents the time when the impact of COVID 19 was most felt in the country. One of the special characteristics of this source is its unsolicited flow of information, meaning that, neither researchers nor particular member of the grouped had the opportunity to interfere or in any way influence direction and content of discussion (Snelson, 2016). This ensures that the data was as natural and reliable as possible.

The study also made use of a wide range of literature on the subject. Research reports, official statements, and news reports were thoroughly reviewed (Snyder, H., 2019). Given the gravity of problem to the nation, there were also statements given heads of prominent tourism companies as well as senior to top government officials on the matter which were also studied and incorporated in the discussion.

\section{Findings and Discussion}

As it would have been the case with any other crises, responses by individual countries against COVID-19 differed greatly (Gosslin el at, 2020). Depending on severity of the outbreak, dynamics of populations, socio-economic status, countries placed themselves at one point or the other between the two extremes i.e. those who preferred a rather passive action to those who opted for a total lockdown. While the rest of the world was systematically opting for a forceful imposition of a lockdown, Tanzania responded to COVID-19 rather cautiously and the country never went to a lockdown. Despite differences in approach, it was made mandatory for all people to take other preventive measures seriously (Mboera et al., 2020). Preventive measures that were enforced in Tanzania included use of PPE, physical distancing, self and compulsory quarantines, selfisolation, and avoiding unnecessary travelling. In addition to such preventive measures taken by citizens, it became necessary that, at some point, restrictions had to also imposed to domestic as well as international travels.

\section{Negative effect of COVID 19 on tourism in Tanzania}

The impact of COVID-19 on tourism in Tanzania became more apparent when major international airlines including Turkish Airline, Emirates, KLM, Qatar, Swiss Air and others were forced to suspend their services in the country. Most airlines announced their decision to cancel their services between $25^{\text {th }}$ and 28 March 2020. Following this development, the Permanent Secretary of the Ministry of Natural Resources and Tourism in Tanzania, Professor Adlof Mkenda, confirmed that tourism is among sectors which had been hit the hardest. Cancellation of flights, closing down of hotels, lodges, restaurants, among other businesses in the sector can be widely felt. Considerable number of jobs have also been lost due to the fall of business. (Tanzania Citizen Newspaper, May 12 ${ }^{\text {in }}$ 2020).

The full-scale impact that COVID-19 is likely to inflict tourism sector in Tanzania is better seen when measured against the actual performance of the sector to the period leading to the outbreak. The pre-COVID-19 contribution of tourism into Tanzania's GDP 
was in excess of $17 \%$. The sector also accounted for around $25 \%$ of the country's total exports (MNRT, 2019). For the year 2018 alone foreign exchange earnings generated by international tourism amounted to USD $2.557 \mathrm{bn}$ and this represented $25.79 \%$ of all goods and service exports (ESRF, 2020). Table 1 below shows the trend in the growth of the sector using two key variables of arrivals and receipts. It is obvious from the statistics that tourism has had a consistent upward annual growth in the entire decade. In this period of only nine years tourism growth seems to have doubled.

Table 1: International Tourism Arrivals and Receipts from Tanzania between 2009 and 2018

\begin{tabular}{|l|r|r|r|r|r|r|r|r|r|}
\hline & 2010 & 2011 & 2012 & 2013 & 2014 & 2015 & 2016 & 2017 & 2018 \\
\hline Arrivals (000) & 783 & 868 & 1,077 & 1,096 & $1,140.1$ & $1,137.1$ & $1,284.3$ & $1,327.1$ & 1,506 \\
\hline $\begin{array}{l}\text { Receipts, (000' } \\
\text { US\$) }\end{array}$ & $1,254.5$ & $1,353.3$ & $1,712.7$ & $1,853.3$ & $2,006.3$ & 1,902 & $2,131.6$ & 2,257 & $2,412.3$ \\
\hline
\end{tabular}

Source: MNRT, 2018

Apart from the already impressive growth, the Government of Tanzania was in a race of achieving even a higher target. The year 2020, which faced this demise, was especially significant to the history and development of tourism sector in the country. It is in 2020 that two million international tourists were expected to have visited the country for the first time in her history. The two million tourists mark is for years now being cited as a key measure of the destination performance (URT, 2015). It may also be noted that this is the second major performance target in the country's history, the first target anticipated Tanzania to receive a total of one million international tourists by the year 2010 (URT, 1999). Unfortunately, as it was the case now Tanzania had failed to achieve its target due to yet another disaster, the Global Economic Crisis that hit the world in 2008/09. The crisis had devastating effects in the US economy was still the major source market for Tanzania. So, the impact of COVID-19 to Tanzania is critical in the sense that it has suddenly vaporized tourism sector's long set ambition.

In its bid to meet the said target, which would mean that the number of tourists had to increase by at least 30 percent between 2018 and 2020, Tanzania had committed an unprecedented effort and resources in upscaling her marketing campaign in both traditional and new international markets. It is at the end of 2018 that Tanzania's National Tourism Board (in-charge of destination promotion) kicked-off the largest ever promotion campaign in China. This campaign, which was to soon be backed up by a Three-Year Strategy to effectively promote Tanzania in China, was to see China becoming one of the leading source markets for Tanzania in three years' time. By 2018 only 32,773 Chinese tourists visited Tanzania the number which, according to the draft Strategy document, is far too small given China's total outbound capacity of more than 230 million tourists a year. In the Strategy, the target was to lift the number of Chinese tourists to Tanzania many folds i.e. from the region of 30,000 to around 150,000 tourists a year. Another thing to note is that the marketing campaign went side by side with the effort to lure more Chinese investors to Tanzania so that they set up facilities and services. This was taken as a tactic to support the strategy under the assumption that local Chinese operators would, on one hand, invest in marketing, but again by making services of Chinese orientation available it would give Chinese travelers a sense of assurance.

Other emerging markets that were in focus in the period of 2018 to 2020 include the Middle East, particularly Israel, where charter groups became a successful market segment for Tanzania. Similar effort was waged by the public as well as private sector 
players to promote Tanzania in her key traditional markets of US and Northern Europe. The visits by former and current Heads of State (President Barack Obama and the President of Switzerland) in 2019 is a strong statement that Tanzania was set to meet and indeed surpass her promotion targets. So, in totality the impact of COVID-19 is in this sense viewed in what Tanzania had already achieved and what it had hoped to achieve.

\section{Massive Investment in Tourism Products}

It is under the current Government administration (2015 - 2020) that Tanzania has seen the largest expansion in development and diversification of tourism product. The Government's decision to revive national airline with a total of around seven (modern and bigger) aircrafts capable of serving regional and international markets had aimed at supporting the marketing efforts of the country. While the national airline was getting back to its feet, there was a parallel initiative on a large-scale expansion of major international airports (Julius Nyerere and Kilimanjaro International Airports). The move was to attract new international airlines while better serve the existing ones.

In this period there has also been substantial investment in the upgrading of Protected Areas, which are the single largest and most important tourism products in the country. The idea was to see a number of Game Reserves are upgraded to now become National Parks (National Parks are the highest rank in protection status in the country). As a result of this initiative, a total six new National Parks were introduced in the year 2019. With this addition, the number of National Parks in the country increased from sixteen to twenty-two in just over a year. Apart from enhancing protection of wildlife resources available, the purpose of this expansion was to help spread tourism to other circuits in the country. It will be noted that one of the challenges with the pattern of growth of tourism in the country was that development was predominantly congested in one geographical area i.e. the northern tourism circuit. Now, the question as to how such product expansion is affected by COVID-19 lies largely on their investment financing.

With more than $80 \%$ of all international visitors coming for nature-based tourism it is not so hard to appreciate the importance of National Parks as being the powerhouse of tourism development in Tanzania. However, while nature looks irresistible to most tourists, what is not clear to many is the amount of cost of maintaining these pristine assets. With regards to expansion of National Parks, large-scale investment is needed in setting up basic infrastructure and facilities to make them visitor-ready (roads, bridges, offices, housing, and recruitment of qualified manpower). As a public good, all National Parks in Tanzania are put under care of one public office i.e. Tanzania National Parks Authority (TANAPA) where they are managed centrally. It would also be noted that, development of National Parks in Tanzania, as is the case elsewhere, is largely financed out of tourism revenue which is collected at entry gates as entry fees and charges imposed on the use of different resources and facilities in the parks. However, what is of great interest to note here is a firm assurance from the Government protection of natural (and other) resources shall not, in any way, be affected even if Tanzania as a whole suffers from reduced number of tourists as a result of COVID-19 (Director General of TANAPA, Dr. Allan Kijazi, at his Television interview, Tanzania Broadcasting Corporation, May 22 $2^{\text {nd }} 2020$ ) .

\section{The Impact of Overdependence on International Source Markets}

Similar to many other destinations in Africa, Tanzania depends heavily on international source markets for her annual arrival counts. For more than two decades now Northern Europe (mainly UK, Italy, France, German and Netherlands) and the US alone constitute 
over a quarter of all tourists that came to Tanzania annually. For example, while Tanzania received around 1.5 million tourists in 2018, nearly 100,000 of them came from the US and around 270,000 came from Northern Europe. The second largest overseas market for Tanzania is Asia, particularly India and China, who together contributed around 80,000 arrivals in 2018.

Table 2 makes it clear that Tanzania's inbound markets are predominantly longhaul. And as already noted, North America and North Europe constitute over $90 \%$ of all tourists that come out of Africa. Notably, it is only six countries in these regions (USA, UK, Germany, Italy, France and Netherlands) that contribute over $60 \%$ of all tourists from the two regions to Tanzania. So, what makes these markets matter at this time is the fact that these are same countries that have been hit the hardest with COVID 19. It is now fair to say that the secret to the speed of recovery of Tanzania's tourism depends largely on how fast Europe and North America contain virus in their population and how quickly their economies rejuvenate.

Table 2: Tourist Arrivals to Tanzania from Leading International Markets, 2010 2018

\begin{tabular}{|l|r|r|r|r|r|r|r|r|r|}
\hline & $\mathbf{2 0 1 0}$ & $\mathbf{2 0 1 1}$ & $\mathbf{2 0 1 2}$ & $\mathbf{2 0 1 3}$ & $\mathbf{2 0 1 4}$ & $\mathbf{2 0 1 5}$ & $\mathbf{2 0 1 6}$ & $\mathbf{2 0 1 7}$ & $\mathbf{2 0 1 8}$ \\
\hline \hline Americas & $\mathbf{7 0 , 5 5 8}$ & $\mathbf{9 5 , 5 0 3}$ & $\mathbf{1 0 0 , 9 8 2}$ & $\mathbf{9 8 , 3 0 6}$ & $\mathbf{1 2 4 , 2 1 8}$ & $\mathbf{9 8 , 4 5 7}$ & $\mathbf{1 1 8 , 3 6 5}$ & $\mathbf{1 2 5 , 6 0 2}$ & $\mathbf{1 3 5 , 6 9 1}$ \\
\hline USA & 49,215 & 47,766 & 65,110 & 69,671 & 80,489 & 66,394 & 86,860 & 87,238 & 94,876 \\
\hline \multicolumn{1}{|c|}{ \%ge } & 70 & 50 & 64 & 71 & 65 & 67 & 73 & 69 & 70 \\
\hline Pacific
\end{tabular}

While outbound capacity of major markets was succumbing to COVID-19, Tanzania's tourism was left to face yet another challenge of a Travel Advisories issued by US Embassy in the country on 25 $5^{\text {th }}$ May 2020, which as noted before, is the leading market for the destination. This Advisory was issued in a call by the Embassy to take US citizens in the country back to US. In the advisory, there is statement that reads "the risk of contracting COVID-19 in Dar es Salaam (the Capital city if Tanzania) is extremely high". This statement comes at this time when the Government of Tanzania and her key tourism promotion institutions were putting up tremendous effort to win back trust of the market, such statements have a high potential of comprising such efforts. 


\section{Impact of Timing of the Outbreak}

COVID-19 hit at the time when Tanzania was in her low tourism season (which usually falls in between January through May) which also means that care is needed when analyzing the true extent of the impact. In the months of January to April, most tour operators in the country are usually busy confirming bookings and settling payments between them and overseas agents for the on-coming tourism season that usually falls between July to October of that year (Figure 1). But, as a result of COVID-19 this was not the case for this year...bookings turned to be a string of cancellations. This is not to say however that cancelations are all uncommon to local companies and hotels, rather it is the sheer scale of it which was devastating. This is how one operator summarized her frustration with these cancelations: "...the only thing I face every time I open my email is almost endless lines of cancellations from my agents...I feel like I should not come near my computer for a while".

Again, the impact of these cancellations should also be conceived in the light of the nature of tourism markets that Tanzania is serving. As already noted, (in Table 2), around $80 \%$ of all tourists from out of Africa come from long-haul markets which translates into higher travelling cost on part of tourists. Now, if the same tourists have been financially affected (by loss of jobs, income or savings), its means that it will take another season(s) before potential travelers become financially stable and local operators begin to see bookings bouncing back to their pre-COVID-19 levels.

\section{Figure 1: Tourist Arrivals to Tanzania between 2012 - 2018 (By Seasons)}

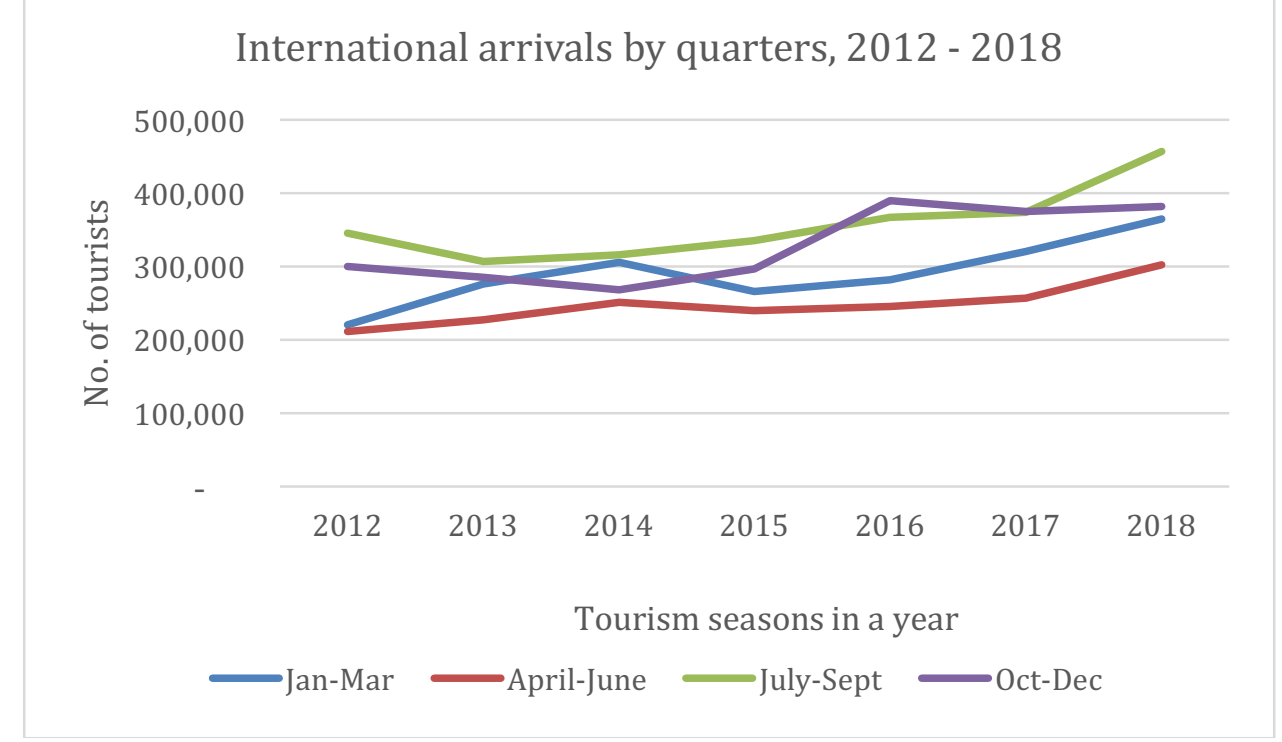

Source: MNRT, 2019

\section{COVID-19 may Induce Changes in Tourist Spending}

There is also a justifiable speculation that loss of income and savings that people in source markets have experienced may go beyond postponement of holidays and trigger changes in their travelling behavior, at least for a few years. Travelers were expected to be more conscious on the cost of vacations while waiting for their economies to regain strength. To a greater extent, the change in spending would mean that travelers may opt for destinations 
closer to home and stay for shorter periods, projections which put destinations in Africa at a greater risk.

\section{The Impact COVID-19 on Tourism Businesses and Employment}

Following a gloomy market outlook, local tourism and hotel operators were reported to be facing the most difficult times in their businesses in decades. In a media interview taken at the height of the outbreak, the Chairperson of Tanzania Association of Tour Operators (TATO), Mr. Wilbard Chamburo, who is himself a prominent operator in the sector, said that most operators face no option but take measures that would help freeze operational and overhead costs. These measures ranged from laying off part of the workforce, reducing salaries to the remaining workforce to total closure/suspension of operations. It was even speculated that about 477,000 jobs and 77 percent of tourism revenue could be lost if the virus spread continued past October 2020 (Mikomangwa, 2020). This estimate is by all means alarming as tourism industry alone supports 623,000 direct jobs and about 1.5 indirect jobs in the economy. Mr. Chambulo further added that, in line with the deteriorating situation, most companies have been facing additional pressure of servicing their bank loans amidst shrinking business.

Although all reports indicate a substantial impact across businesses in the sector, the study by ESRF (2020) makes an opinion that not all businesses are hit in the same way. The hardest hit are the small and micro enterprises (arts and crafts dealers, suppliers, small food and beverages, etc.) who have very limited savings to rely on during periods of inactivity. In this regard, it is expected that women and youth operating in the informal economy will be the most affected group. Studies also predict that in the medium term (July- September 2020), companies in the hospitality industry will continue experiencing vastly reduced occupancy rates and mounting operating losses especially in peak seasons. Given the reduced activity, companies will begin cutting down on costs to remain solvent (ESRF, 2020). On the other hand, a study by Confederation of Tanzania Industries estimated that, due to reduced consumption which is triggered by travel restrictions, key industries in Tanzania have lost up to $50 \%$ of sales and up to $50 \%$ of production output which in turn forced industries to cut down employment by up to 50\% (CTI, May 2020). In a separate interview, Mr. Mahmud Mohamed, the Managing Director of Serena Hotels Africa, said this is the first time in its 40-years history of the company is affected this much (Kamagi, 2020 Tanzania Daily Newspaper). Apart from Serena Hotel, other leading hotel facilities which were forced to suspend their services include Sea Cliff; Serena; Southern Sun; Four Seasons; Hayat Regency-The Kilimanjaro; and Southern Sun.

In addition to an assessment of the overall effects of COVID-19, there are few studies which have taken one step further and attempted to look at its effects on marginalized groups as well as giving a time scale projection. The ESRF report on the impact of COVID-19 in Tanzania is one such studies. In this study (ESRF, 2020 p26) a total of 10 sector (agriculture; mining; manufacturing; construction and real estate, whole and retail trade, financial services and insurance; education, human health and social work; transport and storage; and tourism and hospitality) were ranked on the basis of the impact that COVID-19 has on youth and women and the degree of associated risk each sector is likely to sustain over an immediate (March to April), medium ( May to August), and long term (September to December) time periods. The scale used by the study to measure the level of risks are low, medium, and high. What is of interest in this analysis is the realization that of all sector groups it is tourism and hospitality alone which scored 'high' in all risk variables. 


\section{Positive Impact of COVID-19 on Tourism Sector}

We are almost accustomed to assuming impacts of disasters as being entirely negative. This is simply because we always associate them with injury, loss of life, human displacement, destruction of infrastructure, and disruption of economies. No matter how destructive they might be, such events do offer us an opportunity to look for alternatives or become innovative in what we do. COVID-19 was a wake-up call for Tanzania to now turn their attention to domestic tourism. Although the national Tourism Policy (URT, 1999) makes a strong call for promotion of domestic tourism, there has not been a time when industry players, on their own initiative, pushed a domestic tourism agenda seriously. Due to its low profit potential and limited market, domestic tourism was rarely a subject of discussion at a practical level. It was rather a subject that was usually pioneered by the responsible ministry and its authorities (such as Tanzania National Parks Authority) and community level players but not industry operators.

It is as a result of drastic fall in international tourism market that operators are engaging in the heated discussion as to how to promote domestic tourism. Operators are seen to consistently make a plea to the government to reduce or even suspend some of the licence and Parks entry fees which have long been considered as reasons that push the cost of tourism in Tanzania up. One of the many testimonies from the operators reads: “...for a long time Operators in Tanzania have ignored the importance of domestic tourism. It is high time we realise that domestic tourism acts as a safety valve when international tourism underperforms. It is our call to the government that planning and resources are directed towards promoting and strengthening this segment". Apart from the plea to the government, some of industry operators, especially operators of accommodation facility, have already embarked on a campaign to promote exclusively in the domestic travel market. In the month of May and June 2020 alone, we have seen some of the top-end regional and international lodges and hotels such as Asilia lodges, Serena Hotels and Lodges, and Thana Island lodge vigorously marketing their resident rates in social media. These rates are up to $50 \%$ of the original prices.

\section{Support Given to Sector Operators}

COVID-19 has, in a way, helped strengthening a sense of common understanding that tourism and other sectors require a special attention at times of crisis like this. It is out of these efforts; the central bank of Tanzania issued a directive (on May 12 $2^{\text {th }}$ 2020) asking all commercial banks in the country to enact measures to support business who now struggle to survive. Measures to be taken included, among others, reducing interest fees and giving companies a period of relief in their payment plans. This plan has in many ways gone a long way in lifting the burden off shoulders of tourism entrepreneurs. It is everyone's hope that this initiative will remain to be a reference for financial institutions for the need to strike for win-win negotiations with industry operators, whenever the country in held in grips.

\section{Recommendations}

What is now most important to all stakeholders is focus on winning back trust from the world markets. They should remember, the decision to travel to a particular destination is largely based on the perception of safety level at the place. Re-establishing public perceptions following a disaster is crucial in reassuring potential visitors and, by doing so, 
it is assisting the affected areas in their recovery effort (Rossello et al., 2020). In addition to seeking to positively influence visitor perceptions, addressing risk perceptions and behaviors of relevant tourism stakeholder is critical for effective disaster response (Kozak et al., 2007; Park \& Reisinger, 2010).

Efforts done by the Government especially through the two ministries of health and tourism in protecting lives once air traveling (domestic and international) and tourism reopen are commendable. The two Ministers have been seen to be deeply concerned and indeed cover an extra mile in ensuring that the preventive and medical interventions are in place. Already Draft SOP for ensuring safety in tourism and hospitality services (MNRT, May 28 ${ }^{\text {in }}$ 2020) and Health Travel Advisory No.3 (MHCDEC, May 18 ${ }^{\text {th }}$, 2020) have been issued to the public for their comments and implementation. It is necessary at this stage that more efforts are directed in ensuring that these Standards are readily available to activate their wide use in sensitizing all players in the sector, including overseas diplomatic representatives, to take interest in these protocols and ensure that they are properly equipped to act in the right way. It should also be their duty to timely and correctly inform the market on developments so far taken.

Although efforts are already underway to elevate the status of domestic tourism in the country, which includes among others, commissioning of the first domestic tourism promotion strategy by the National Marketing Board (TTB, 2018), tourism domestic market is still limited. Studies continue to cite culture, mindset, lack of disposable income vis-a-vis cost of taking tourism vacations, and absence of a dedicated promotion strategy as being main causes for a stagnant domestic tourism market.

Even at the height of pandemic Tanzania continued to cling on hope that the scourge days are numbers and that things will in someday return to normalcy. It took a great courage and foresight for the destination to stay focused and reassuring. The national marketing board and her counterparts continued with the marketing work; they were keen to communicate a message that cautions but yet remind them that Tanzania awaits them once the skies open. It is critical that Tanzania struggles to stay in the minds of visitors especially when they are expected to alter their traveling patterns and behavior once COVID-19 is over.

The last reminder that this paper makes is for countries to realize the importance of always being prepared for the unexpected. Although the Government and players have been able to relatively quickly react and save the sector from a total collapse or enable them bounce back rather quickly, it is high time now that disaster risk management strategies are in place, both at a destination and regional level. For almost a decade now, as a community, East Africa has made commendable effort to promote its block as a single but diversified block. Among other things this approach was expected to offer visitors better experience through richer and diverse product package. However, at times, the divided struggle to combat spread of the Virus helped to show a rather fragmented than a destination block. Therefore, a call is made to block to engage in an initiative for a regional level disaster response strategy.

\section{Conclusion}

COVID-19 is undoubtedly a pandemic that will leave travel and tourism sectors with hardto-heal scars. The severity of the impact to many countries in Africa lies in the two variables time and space the facts which is a solemn reminder to its most destinations of a need to diversity and develop their own internal markets. Differences in approach to its containment adopted by destinations, should be an expression as to how they are variedly 
endowed and how best they interpret their economic and technological conditions to achieve results. What all destinations seem to share however is a hope that someday the world will either be free from the pandemic or will have learned to live with it. Despite extent of the impact however there is hope to see tourism live up to its promise of being a resilient industry. As the largest and growth sector on a global scale, it is expected to play a catalyst role for the world in its bid of regain ng the socio-economic stability after the pandemic (Ranasinghe et al., 2020).

\section{Research Limitations and Future Direction}

The study used qualitative methods so as to benefit from an in-depth understanding of peoples' perception and reaction (Rahman, 2017; Queirós et al. 2017; Ochieng, 2009). However, the use of quantitative methods could generate data that would allow comparison in time and space. Again, although the sample was as much as possible representative small and micro operators in the sector are usually not part of the social media groups from which most data was taken. Given the scale of the impact that such disasters have to both destinations and source markets, it is still uncertain as to how quickly travel volume will bounce back to its previous levels. Hence, in addition to knowing the scale and nature of the impacts it is important for future research to inquire on practical recovery strategies that particular destinations may adopt. In this way, this paper seconds the proposal by Dwyer \& Horney, (2014) which calls for more inquiry on disaster recovery indicators tools. Research with a focus on post-disaster marketing are also highly relevant and recommended in the future. After all this, the interest should now be to determine how destinations will now be promoted. It is most likely that post-pandemic travelers will not be the same, reduced savings and income will force destinations to compete with one another in-terms of price, facilities and other features.

\section{References}

Branthwaite, A., \& Patterson, S. (2011). The power of qualitative research in the era of social media. Qualitative Market Research: An International Journal, 14(4), 430440.

Business Correspondent (2020), "Fresh hope for tourism amid COVID-19 calamity", available at: ahttps://www.thecitizen.co.tz/news/-Fresh-hope-for-tourism-amidCovid-19-calamity/1840340-5549862-e3wnlk/index.html, (accessed May 13 ${ }^{\text {th }}$ 2020)

CNN Business (2020), "Tens of thousands of airline jobs are at risk as travel plunges", 6

CNN. (2020). What will travel look like after coronavirus? available at: https://www.cnn.com/travel/article/coronavirus-travel-industry-changes/index.html (accessed 31 2020)

Conde Nast Traveller. (2020). Before and after: How coronavirus has emptied tourist attractions around the world. available at: https://www.cntravellerme.com/beforeand-after-photos-tourist-attractions-during-coronavirus (accessed March 31, 2020)

Confederation of Tanzania Industries (2020 May). Analysis of the impact of coronavirus disease 2019 (COVID 19) outbreak to industries in Tanzania. Report.

Dodds, R., and Butler, R. (Eds.). (2019). Over tourism: Issues, realities and solutions. De Gruyter.

Dwyer C and Horney J. (2014). Validating Indicators of Disaster Recovery with Qualitative Research. PLOS Currents Disasters. Edition 1.

Economic and Social Research Foundation (2020 May). Rapid Social Economic Impact Assessment of COVID 19 in Tanzania. Report. 
Forbes. (2020), "What will travel be like after the coronavirus?", available at: https://www.forbes.com/sites/christopherelliott/2020/03/18/what-will-travel-be-likeafter-the-coronavirus/\#4febdd623329 (accessed March 31 2020)

Gössling, S., Scott, D., and C. Hall, C. H. (2020). Pandemics, tourism and global change: a rapid assessment of COVID-19, Journal of Sustainable Tourism. 1-20.

ICAO (2018). Travel and Tourism a Force for Good in the World, Accessed November 7 , 2018, www.icao.int/Meetings/iwaf2018/Documents/Travel\%20and\%20Tourism.pdf (accessed March 31 2020)

ILO Guidelines on decent work and socially responsible tourism, 2017.

Jaume Rossello, Susanne Becken and Maria Santata-Gallego (2020), The effects of natural disasters on international tourism: a global analysis, Tourism Management (79 (2020) 1044080.

Kamagi, D., (2020) from Tanzania Daily News titled Tanzania: Covid-19 Outbreak Forces Hotel Breaks.

Kapoor, K. K., Tamilmani, K., Rana, N. P., Patil, P., Dwivedi, Y. K., \& Nerur, S. (2018). Advances in Social Media Research: Past, Present and Future. Inf Syst Front. 20. $531-558$

Mikomangwa, P., (2020) from the Exchange titled Tanzania: How COVID-19 Threatens Tourism Labour in Tanzania.

Minister for Health, Community Development, Gender, Elderly and Children (MHCDEC), Travel Advisory No.3 of 18th May, 2020. Dar es Salaam.

Ochieng, P. A. (2009). An analysis of the strengths and limitation of qualitative and quantitative research paradigms. Problems of Education in the 21 st Century, 13, 13.

Paryono. (2017, September). The importance of TVET and its contribution to sustainable development. In AIP Conference Proceedings. 1887(1), p. 020076).

Peter Tarlow, P (2005), Issues in Health, Safety and Security (no publisher and other details).

Queirós, A., Faria, D., \& Almeida, F. (2017). Strengths and Limitations of Qualitative and Quantitative Research Methods.

Rahman, M. S. (2017). The Advantages and Disadvantages of Using Qualitative and Quantitative Approaches and Methods in Language" Testing and Assessment" Research: A Literature Review. Journal of Education and Learning, 6(1), 102-112.

Ranasinghe, R., Damunupola, A., Wijesundara, S., Karunarathna, C., Nawarathna, D., Gamage, S., Amaya Ranaweera, A. and Idroos, A. A., (2020). Tourism after Corona: Impacts of covid 19 pandemic and way forward for tourism, hotel and mice industry in Srilanka.

Seraphin, H., Sheeran, P., \& Pilato, M. (2018). Over-tourism and the fall of Venice as a destination. Journal of Destination Marketing \& Management, 9, 374-376.

Snelson, C. L. (2016). Qualitative and Mixed Methods Social Media Research: A Review of the Literature. International Journal of Qualitative Methods. 1-15

Snyder, H. (2019). Literature Review as a Research Methodology: An Overview and Guidelines. Journal of Business Research, 104. pp.333-339.

Sofronov, B. (2018). The Development of the Travel and Tourism Industry in the World. Annals of Spiru Haret University. Economic Series, 18(4), 123-137.

Tanzania Tourist Board (2012). International Tourism Marketing Strategy. Dar es Salaam. Tanzania Tourist Board (2019). Marketing strategy for Tanzania tourism in China (Draft). Dar es Salaam. 
United Republic of Tanzania (2015), Chama cha Mapinduzi (CCM), General Election Manifesto,

UNWTO (2020 May 29th). COVID 19 Related Travel Restrictions, A Global Review for Tourism. Madrid, Spain. Forth Report.

UNWTO (2020 May). World Tourism Barometer May 2020: Special focus on the Impact of COVID-19. Madrid, Spain.

URT (1999). National Tourism Policy of Tanzania. Government Printer. Dar es Salaam.

World Bank. (2020b), "International tourism, number of arrivals", available at: https://data.worldbank. org/indicator/ST.INT.ARVL. (Accessed on April 4, 2020).

World Economic Forum (2020), "This is how coronavirus could affect the travel and tourism industry", available at: https://www.weforum.org/agenda/2020/03/worldtravel-coronavirus-covid19-jobs- pandemic-tourism-aviation/ (Accessed on March 20, 2020).

World Travel and Tourism Council (2018), "Economic Impact 2018 World", available at: https://www.wttc.org/-/media/files/reports/economic-impact-research/regions 2018/world2018.pdf. (Accessed on March 20, 2020).

WTTC (unpublished, 2020). The economic impact of travel \& tourism. (Accessed on March 20, 2020). 